plan is for surgeon and patient to part at once. If, in a moment of aberration, one has ordered a $+2.0 \mathrm{sph}$. for a myope of $-2.0 \mathrm{D}$., no wonder if the latter be querulous. But many cases, indeed most, are not so straightforward as this. If a patient appears to be unreasonable there is, we believe, usually some cause for it apart from the actual ministrations of the doctor. Some people are very hard to please and some would seem to have made up their minds before the examination starts to be troublesome. But often the general health is at fault and if you find evidence of advanced vascular disease in the fundus oculi you will be able to make allowances for asperity of temper and other short comings. A sense of humour helps some people, for there is often something ludicrous in these people's fancies; but it is just as well to keep your fun to yourself unless you know the patient very well indeed.

It seems likely that, under state control, some patients will continue to be dissatisfied; and that a large proportion of the profession will be as well, seems to be as certain as the fact that Mrs. Gamp liked her beer drawn mild. That eminent practitioner would surely have resented interference with her professional liberty and in our mind's eye we can see her consigning the bill to Jonadge's belly along with the Ankworks package.

When we were young a story went round the town of a dissatisfied patient who called on an ophthalmologist of international reputation to say that the glasses which had been : ordered were not : what he wanted. He adopted rather a truculent attitude and ended up by saying "I'm not. satisfied." "Well, I am," retorted the oculist and the patient was dismissed. With free treatment for all there will be nothing to prevent a patient from consulting a different doctor every other week. What will be the reaction of those in authority, as the forms come home to their official pigeon holes, when it is found that Diogenes has consulted every doctor from Alpha to Omega in the short period of six months?

\title{
OPHTHALMOLOGICAL SOCIETY OF AUSTRALIA
}

\section{Discussion on blindness in Prisoners of War}

A MEMORABLE meeting was held in Melbourne on May 2 when the Victorian section of the Ophthalmological Society of Australia (B.M.A.) met to discuss the blindness that affected Prisoners of War. Dr. F. G. Fenton was in the chair.

Dr. Robin Orr described the types of disease he had observed and the various conditions with which these could have been associated A corneal condition referred to as " granular cornea", 
caused little serious trouble and cleared up perfectly ; 800 Australians had been affected. Great numbers of men, however, developed visual loss similar to that of retro-bulbar neuritis. Dr. Orr examined two thousand affected Australians and about five hundred British and Dutch. As many were examined and tested on numerous occasions some idea of the colossal amount of work done under very trying conditions can be imagined. Detailed reports of most of those patients were still in Dr. Orr's possession.

European food lasted until early in March, 1942. Deficiency diseases, beri-beri, skin and corneal lesions had appeared by June. By July. it was realised that not all the visual loss was of corneal origin, and that the nervous tissues were being involved. Most men reported with vision of about $6 / 9$ but some not until it was $6 / 60$. The discs at first showed slight congestion and rarely one or more retinal haemorrhages. Later; unless acuity improved, partial pallor of the discs usually appeared. The fields were mapped out as a rule with $2 \mathrm{~mm}$. white or a $3 \mathrm{~mm}$. red object at 2 metres. Men did not give accurate results until they had been given considerable practice at scotometry.

The incidence reached fifteen cases per thousand per week. As a rule there was a lag of one to two months after a drop in diet before a rise in incidence of visual failure appeared. Occasionally a man whilst on good diet developed " retrobulbar neuritis" and though tobacco excess was unlikely it was found that non-smokers were affected as well as those who smoked heavily. No alcohol was available. Recurrent malaria and dysentery frequently preceded visual failure, but in the first epidemic many had not had either disease. Some mild cases cleared up after a sharp attack of diarrhoea-not dysentery.

No night blindness, scurvy, keratomalacia or Bitôt's spots were found. Captain Woodruff constructed a photomoter and though night blindess was complained of the only genuine case of night blindness found was in a man with retinitis pigmentosa. The first cases were treated with vegemite 2 drachms daily, and rice polishings, from 2 to 3 ounces daily. The latter were contaminated and very unpleasant to take. Many other preparations including grass soup and leaf extracts were given, but mostly in very small quantities. Marmite was used, 2 drachms daily, by the end of September, 1942, with reasonably satisfactory results. Thiamin appeared valueless but it was possible to give only 6 daily injections of 2 milligrammes each. Riboflavin by mouth produced results no better than marmite, but then the patients treated were mainly older ones. The rice polishings contained only one tenth the quantity of riboflavin that was expected.

Dr. Orr discussed the problem of the return of these men to civilian life, and the need for a consideration of their pensions. 
Many who might have central vision of $6 / 9$ might not be safe as railway or naval employees. It was the position of the scotomata rather than their extent that mattered. As a rule the scotoma was between the fixation point and the blind spot and usually close to the former.

Dr. Orr showed his original charts prepared at night under difficult conditions and with scrounged and even locally made ink. Whatever was deficient at Changi, it was not grit and determination.

Professor A. W. Mulock Houwer who had been interned in N.E.I. by the Japanese for three and a half years summarised his opinions on the condition that he prefers to call " amblyopia with polyneuropathia." " Camp eyes " was the title given to it during internment. Health was apparently fair until early in 1944 when his camp was moved to the mountains where the cold, the replacement of red by polished rice and bacillary dysentery took heavy toll of the occupants. He was struck by the absence of camp eye amongst children, women and Eurasians. He knew of only one female patient. Middle aged and older men were most affected. There appeared to be an individual susceptibility as a number of internees died from gross deficiency diseases without any visual loss. The onset was usually five to seven months after internment. It often followed an attack of bacillary dysentery. Frequently the patient would complain that one day he noticed he could not recognise his friends, and that this increased for a week or two and then remained stationary. Most of these patients at this time had burning soles to their feet but as knee jerks were always normal and ankle jerks usually so, the neurologists hesitated to diagnose beri-beri.

He was struck by the following fundus changes in nearly all cases: (1) the foveolar reflex was absent more frequently than usual in each age group, (2) a delicate granular appearance at the macula, (3) small yellow and black spots in or near the macula. In some older cases drusen and in a few recent ones haemorrhages were present. In one or two men the drusen were very extensive. In some old cases more or less temporal pallor was present, though in others the disc appeared to be normal. He did not observe anv hyperaemia or blurring of the disc.

Professor Mulock Houwer thought that lack of B1 was the chief cause, and that lack of other members of the B group and a poor diet consisting chiefly of carbohydrates were contributory factors. He had seen recent cases recover when given thiamin, but the doses were much greater than those given by $\mathrm{Dr}$. Orr. He advised that patients should be given thiamin and the rest of the B group, especially nicotinic acid. He recommended also a diet that was poor in carbohydrates as the disproportion between intake of much 
carbohydrates and little $B$ may play an esential part in causing central scotomata.

Dr. R. B. Maynard spoke of his three and a half years as a P.O.W. in the Changi Camp and gave first hand information of retrobulbar neuritis as he had had the condition. He was surprised to find the " reds" missing in the specimens stained by his technician. His condition responded to marmite. He had been able to keep two specimens of eyes with advanced "retrobulbar neuritis" and several specimens of optic nerves, chiasma, and one whole brain. His report on these was held over until selective staining had been done.

Dr. S. R. Gerstman who is in charge of the "Stonnington" Rehabilitation Centre for blinded P.O.W. discussed the work and conditions there. Fifty-six patients have been admitted and twentyfour discharged for various reasons :-(1) have obtained work commensurate with their poor state of vision. (2) Lack of interest in the work of the centre and being a rather bad influence on other patients. (3) Family worries especially interstate patients, being separated from their families after five years previous separation.

The visual acuity of the thirty-two patients that are there at the moment is (1) up to and including. $3 / 60-10,(2)$ up to and including $6 / 60-12$; (3) up to and including $6 / 36-3$, (4) better than $6 / 36-3$.

Treatment consists of a very full diet and practically unlimited quantities of fresh eggs, meat, vegetables and fruit. Vitamin B complex in form of marmite and vegemite is always on the table for the use of patients.

With regard to spectacles, some of the patients appreciate a high plus lens $(+40)$ for reading. Others prefer a magnifying glass to read letters and newspapers.

Occupations include gardening, leather wotk, weaving, pottery and carpentry. There are classes in Braille and touch typing. The chief difficulty is a shortage of trained personnel skilled in teaching the partially sighted.

There is plenty of entertainment inside and outside the centre. Inside, there are wireless, cards and table tennis, at which the patients are quite adept. Outside, there are numerous motor outings, dances and the legitimate stage. Altogether, the patients are verv contented, with the exception of some from other states, who naturally feel that after some five years away from their families, another breach is a bit too much to expect of any man. It is this point which is important if there is any future decision about sending these patients to St. Dunstan's. Personally, I am of the opinion that it would be reasonable to send the single men and only those married ones who were enthusiastic enough to realize that their training would be of great importance in their future lives." I do not think any coercion should be used. 
Dr. Kevin O'Day thanked the speakers for the papers which bore eloquent testimony to the devotion and skill of the medical officers in the P.O.W. camps in Malaya.

In the routine examination of the repatriated P.O.W's. at Heidelberg Military Hospital, the fields were examined by Major Hughes himself on the Bjerrum screen at two and four metres. There was no evidence of any field defect which might lead one to suspect a lesion in the nerve, that is, there was nothing resembling an arcuate scotoma extending from the blind spot. The most constant finding was a small scotoma just within the five degree circle on the nasal side of fixation with no evidence even with the small objects, of any connection with the blind spot. This scotoma might occasionally extend as a ring encircling the fixation point. At other times, isolated scotomata might be found along this circle. In severe cases there was a dense central scotoma, and the patient was unable to see the fixation mark on the screen. Some would fix with one edge of the scotoma with the consequent shifting of the blind spot across the screen. The edges of the scotoma were shelving.

The appearance of the discs was deceptive. He was not convinced that there was any evidence of atrophy. There was no formation of new tissue on the disc. As many normal cases were seen at the same time with no history of visual impairment, and with normal vision and full visual fields it was possible to compare. the observations with normal. Amongst the normal were many cases of "pale discs" and " temporal optic atrophy." It is of course well known that the appearance of the normal disc may vary within wide limits and the speaker did not see any nerve-head which he would be prepared to say was atrophic. It was thought that red free light might be of help in discovering atrophy of the nerve fibre bundles. With the aid of the Physiology and Natural Philosophy departments of the Melbourne University the fundi of normal individuals were examined using the reflecting ophthalmoscope with a direct current arc with large carbons, and with mercury vapour and sodium vapour lamps. Even in the normal, the appearance was so deceptive it was felt that the examination was of no value. The speaker certainly wanted much better evidence than that presented by the red free light. Ophthalmoscopic examination of the central area of the fundus did not reveal anything definite. The absence of a fovealar reflex, to which Dr. Mulock Houwer referred, was looked for. It was found to be absent in many normal individuals, and apparently could not be regarded as a sign of any value. No other appearances were seen in the central area which could be interpreted as being definitely abnormal.

The speaker thought that the lesion could be explained on a 
purely retinal basis, and that the lesion was in Henle's fibre layer. Sections cut through the centre of a normal fovea centralis show that a few cone nuclei still remain internal to the external limiting membrane, with an occasional nucleus of a bi-polar cell. The fibres of the cone cells running up to form synapses with the bi-polars are shortest in the centre of the fovea. Going away from the centre the fibres gradually lengthen until they actually run parallel with the limitans for some distance, and it would appear that the longest fibres are those toward the periphery of the fovea. It is well known that Henle's fibre layer is prone to degeneration-in fact it appears to be impossible to fix this particular region successfully when preparing globes for embedding. The speaker suggested that the toxic agent causing the scotoma in these cases might have its first and greatest effect on the longest fibres of Henle's layer, a layer prone to degeneration because of its poor blood supply. As these fibres belong to the cones at the periphery of the fovea, the corresponding field defect is just within the five degree circle.

\section{ABSTRACTS}

\section{I.-THERAPEUTICS}

(1) Bloomfield, S. (New York).-The use of tyrothricin, a bacterial extract, in the treatment of marginal ulcers of the cornea. Amer. Jl. Ophthal. Vol. XXVII, p. 500, 1944.

(1) Bloomfield comments that the antiseptic effect of tyrothricin is principally due to its gramicidin content. Tyrothricin is prepared from cultures of Bacillus brevis, an aerobic sporulating saprophyte commonly found in sewage and soil. It is a stable mixture of gramicidin and tyrocidine.

The author used drops of tyrothricin suspension in the affected eye every three hours, and tyrothricin ointment in the conjunctival sac at night time. He reports four cases of marginal ulceration of the cornea, resistant to other forms of treatment, which responded quickly to tyrothricin and were healed in 5 to 14 days.

\section{H. B. Stallard.}

(2) Laval, T. (New York).-Anterior chamber irrigation with sulfadiazine. Amer. Jl. Ophthal., Vol. XXVII, p. 527, 1944.

(2) Laval describes the case of a woman, aged 60 years, who vomited after the section had been made in a cataract operation. Gastric contents entered the eye. The anterior chamber and the conjunctival sac were irrigated with sodium, sulphadiazine 10 per 